\title{
Genome of extreme halophyte Puccinellia tenuiflora
}

Rui Guo ${ }^{1 \dagger}$, Long Zhao ${ }^{2,3 \dagger}$, Kaijian Zhang ${ }^{4 \dagger}$, Dan Gao ${ }^{4}$ and Chunwu Yang ${ }^{2 *}$ (D)

\begin{abstract}
Background: Puccinellia tenuiflora, a forage grass, is considered a model halophyte given its strong tolerance for multiple stress conditions and its close genetic relationship with cereals. This halophyte has enormous values for improving our understanding of salinity tolerance mechanisms. The genetic information of $P$. tenuiflora also is a potential resource that can be used for improving the salinity tolerance of cereals.

Results: Here, we sequenced and assembled the $P$. tenuiflora genome $(2 n=14)$ through the combined strategy of

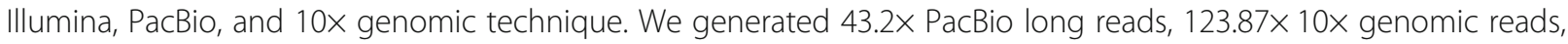
and 312.6x Illumina reads. Finally, we assembled 2638 scaffolds with a total size of $1.107 \mathrm{~Gb}$, contig N50 of $117 \mathrm{~kb}$, and scaffold N50 of $950 \mathrm{~kb}$. We predicted 39,725 protein-coding genes, and identified 692 tRNAs, 68 rRNAs, 702 snRNAs, 1376 microRNAs, and $691 \mathrm{Mb}$ transposable elements.

Conclusions: We deposited the genome sequence in NCBI and the Genome Warehouse in National Genomics Data Center. Our work may improve current understanding of plant salinity tolerance, and provides extensive genetic resources necessary for improving the salinity and drought tolerance of cereals.
\end{abstract}

Keywords: Genome, Halophyte, Salinity, Puccinellia tenuiflora

\section{Background}

Salinity stress affects over $6 \%$ of the global land area and is a severe problem that limits agriculture $[1,2]$. Halophytes are remarkable plants that tolerate high salinity that would kill $99 \%$ of other plant species (glycophyte), and are applied to improve saline soil $[3,4]$. Some extreme halophytes can survive salinity levels $>1000 \mathrm{mM}$ $\mathrm{NaCl}$, whereas glycophytes, such as rice and Arabidopsis, can only survive $50-100 \mathrm{mM} \mathrm{NaCl}[4,5]$. Most botanists believe that these salt-sensitive glycophytes may provide limited insights into mechanisms of salinity tolerance, and that extreme halophytes may have enormous values for improving our understanding of salinity tolerance mechanisms [4-6]. Given that many important crops are

\footnotetext{
* Correspondence: yangcw809@nenu.edu.cn

${ }^{+}$Rui Guo, Long Zhao and Kaijian Zhang contributed equally to this work. ${ }^{2}$ Key laboratory of Molecular Epigenetics of Ministry of Education (MOE), Northeast Normal University, Changchun 130024, China

Full list of author information is available at the end of the article
}

gramineous, understanding the salinity tolerance mechanisms of gramineous halophytes will be helpful in improving the salinity or drought tolerance of cereal crops. Although the genomes of several salinity-tolerant plant species have been reported [7-10], the genome of an extreme Gramineae halophyte is unavailable. Puccinellia tenuiflora $(2 n=14)$ is a perennial halophyte of the Gramineae and is distributed in Asian and European grasslands $[3,11,12]$. It is a forage grass with high nutritional value and strong tolerance for multiple stress conditions, such as drought, disease, and chilling [3, 11, 12]. $P$. tenuiflora can survive at $\mathrm{pH} 10$ and $900 \mathrm{mM} \mathrm{NaCl}[3$, 11-14] and can grow normally and produce seeds under some extreme soil conditions $(2-3 \%$ salt content and $\mathrm{pH}>10)[14,15]$. Given these qualities, $P$. tenuiflora has been used to recover and exploit saline grasslands or croplands in northern China $[14,15]$. A growing number of molecular studies have focused on P. tenuiflora [12, 16-28]. Currently, P. tenuiflora is recognized as a model

(c) The Author(s). 2020 Open Access This article is licensed under a Creative Commons Attribution 4.0 International License, which permits use, sharing, adaptation, distribution and reproduction in any medium or format, as long as you give appropriate credit to the original author(s) and the source, provide a link to the Creative Commons licence, and indicate if changes were made. The images or other third party material in this article are included in the article's Creative Commons licence, unless indicated otherwise in a credit line to the material. If material is not included in the article's Creative Commons licence and your intended use is not permitted by statutory regulation or exceeds the permitted use, you will need to obtain permission directly from the copyright holder. To view a copy of this licence, visit http://creativecommons.org/licenses/by/4.0/ The Creative Commons Public Domain Dedication waiver (http://creativecommons.org/publicdomain/zero/1.0/) applies to the data made available in this article, unless otherwise stated in a credit line to the data. 


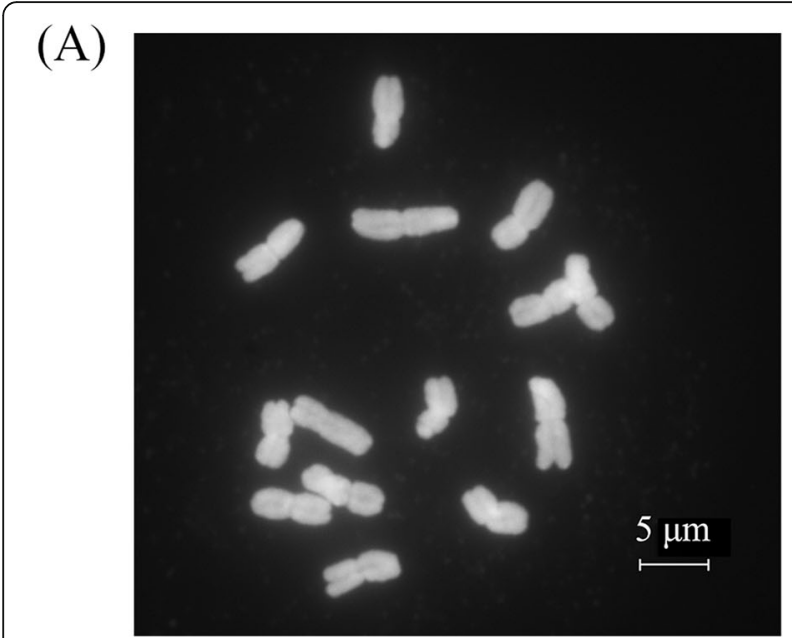

(B)

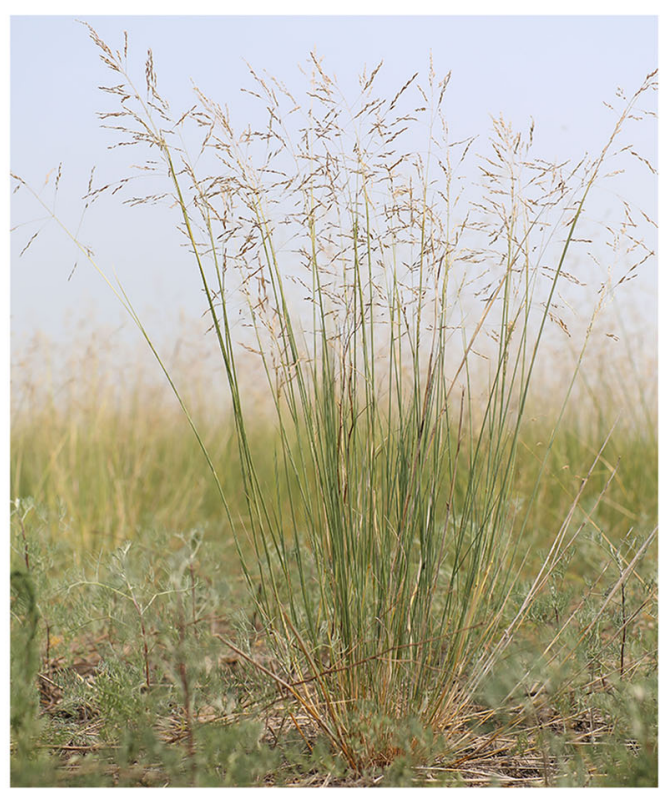

Fig. 1 Chromosome number (a) and habitat (b) of P. tenuiflora

halophyte $[3,12]$. Unfortunately, the genomic sequence of $P$. tenuiflora is unavailable. Here, we provide first report on the $P$. tenuiflora genome. Our work may provide extensive genetic resources for improving the salinity or drought tolerance of cereals.

\section{Construction and content Evaluation of genome size}

Taxonomy characteristics of Puccinellia tenuiflora are available at Flora of China (http://www.efloras.org/ florataxon.aspx?flora_id=2\&taxon_id=200026128). We surveyed the chromosome number of $P$. tenuiflora according to Kato et al. [29]. Total genomic DNA was extracted from fresh leaves. We used the conventional method to estimate the $P$. tenuiflora genome size. Briefly, we generated $49 \mathrm{~Gb}$ of high-quality short-insert Illumina reads to analyze the $K$-mer frequency of distribution [30]. Genome size was calculated using the following formula: Genome size $=$ total $K$-mer number $/ K$ mer depth [30,31], in which $K$-mer depth is the peak value of $K$-mer distribution. The chromosome number of $P$. tenuiflora is 14 (Fig. 1 ). Our $K$-mer analysis showed that the genome size of extreme halophyte $P$. tenuiflora was $1.303 \mathrm{~Gb}(2 \mathrm{n}=14)$ and the genome was complex, with $1.56 \%$ heterozygosity and $65.5 \%$ repeat content (Table 1).

\section{Genome sequencing}

Illumina paired-end (PE) libraries were constructed with short insert sizes of 250 and $450 \mathrm{bp}$. Illumina mate-pair (MP) libraries were constructed with insert sizes of 2, 5, and $10 \mathrm{kbp}$ (Table 2). We generated $209.13 \mathrm{~Gb}$ of raw data by the PE libraries, and $197.38 \mathrm{~Gb}$ of raw data by the MP libraries. The Illumina libraries were sequenced on Illumina HiSeq XTen platform. We also sequenced $56.12 \mathrm{~Gb}$ of PacBio long reads and $161.03 \mathrm{~Gb}$ of $10 \times$ genomics barcoded reads (Table 2).

\section{Genome assembly}

Because the $P$. tenuiflora genome is highly complex and repeated, its genome was assembled by a combined strategy of PacBio (third-generation), 10× genomic technique, and Illumina Hiseq (second-generation). We generated $312.6 \times$ reads of Illumina, $43.2 \times$ read of PacBio and $123.87 \times$ reads of $10 \times$ genomic. First the PacBio sequences were corrected for errors. The accurate sequences of PacBio were assembled into primary contigs based on FALCON (Branch 3.1) [32] and FALCON-Unzip software (https://github.com/PacificBiosciences/FALCON_unzip).

After treatment with FALCON-Unzip software, we corrected errors of these contigs using PacBio sequences based on quiver software [33] and using Illumina data based on pilon software [34], and finally obtaining consensus sequences of high quality. Next, we used Illumina long reads of 2,5 , and $10 \mathrm{~kb}$ to elongate and combine the preassembled contigs into scaffolds based on SSPACE software [35], and then used 10x genomics linked-reads to further elongate and combine the scaffolds based on $10 x$

Table 1 Results of K-mer analysis. The K-mer was defined as $17 \mathrm{bp}$ to assess $P$. tenuiflora genome size by the following formula: total $K$-mer number/K-mer depth. The heterozygous ratio was determined by the number of heterozygous $K$-mer/total $K$-mer number

\begin{tabular}{ccccc}
\hline K-mer & Depth & n_kmer & Genome_size (Mb) & a Revised genome_size (Mb) \\
\hline 17 & 31 & $41,192,925,796$ & 1328.80 & 1303.06 \\
\hline
\end{tabular}

${ }^{\mathrm{a}}$ Excluded effects of uncorrected $K$-mer 
Table 2 Raw data of $P$. tenuiflora sequencing

\begin{tabular}{llll}
\hline Libraries & Insert size & Total data $(\mathrm{Gb})$ & Sequence coverage $(\mathrm{X})$ \\
\hline Illumina reads & $250 \mathrm{bp}$ & 122.03 & 93.87 \\
& $450 \mathrm{bp}$ & 87.1 & 67 \\
& $2 \mathrm{~kb}$ & 70.29 & 54.07 \\
& $5 \mathrm{~kb}$ & 51.3 & 39.46 \\
& $10 \mathrm{~kb}$ & 75.79 & 58.3 \\
PacBio reads & $20 \mathrm{~kb}$ & 56.12 & 43.17 \\
10× Genomics & & 161.03 & 123.87 \\
Total & - & 623.66 & 479.74 \\
\hline
\end{tabular}

FragScaff software. Lastly, we used Purge Haplotigs software (https://bitbucket.org/mroachawri/purge_haplotigs/ overview) to filter the redundant sequences caused by high heterozygosity. Finally, we assembled 2638 scaffolds with a total size of $1.107 \mathrm{~Gb}$, contig N50 of $117 \mathrm{~kb}$, and scaffold N50 of $950 \mathrm{~kb}$ (Table 3).

\section{Genome annotation}

\section{Annotation of replicate sequences}

Transposable elements (TEs) of the P. tenuiflora genome were annotated. We used two methods to find the TEs. The first method was RepeatMasker (version 3.3.0) to discover TEs in an integrated known replicate sequence library (Repbase 15.02) and the de novo replicate sequence library constructed by RepeatModeler (Version 1.0.5) [36, 37], RepeatScout [38], and LTR_FINDER [39]. The second method detected TEs in the P. tenuiflora genome using RepeatProteinMask by searching against the TE protein database [37]. We identified $691 \mathrm{Mb}$ transposable elements (62.44\% of the total sequence),
Table 3 Assembly results of $P$. tenuiflora genome

\begin{tabular}{llllll}
\hline Sample ID & \multicolumn{2}{l}{ Length } & & \multicolumn{2}{l}{ Number } \\
\cline { 2 - 3 } & Contig $(\mathrm{bp})$ & Scaffold $(\mathrm{bp})$ & & Contig & Scaffold \\
\hline Total & $1,095,388,111$ & $1,107,157,923$ & & 14,036 & 2638 \\
Max & 803,180 & $7,202,224$ & & - \\
Number $>=2000$ & - & - & & 13,349 & 2183 \\
N50 & 117,188 & 949,910 & & 2936 & 338 \\
N60 & 97,500 & 788,398 & & 3958 & 465 \\
N70 & 80,583 & 601,430 & & 5194 & 625 \\
N80 & 64,330 & 447,145 & & 6714 & 839 \\
N90 & 45,138 & 278,370 & 8711 & 1152 \\
\hline
\end{tabular}

including $580 \mathrm{Mb}$ of LTR retrotransposons (52.43\%) (Table 4).

\section{Annotation of protein-coding genes}

A combined strategy (de novo-, homolog-, and RNAseq-based predictions) was used to annotate proteincoding genes in the $P$. tenuiflora genome using the following software: Augustus (version 3.0.2) [40, 41], Genescan (version 1.0) [42], Geneid [43], GlimmerHMM (version 3.0.2) [44], and SNAP [45]. The homologous sequences of six species (Zea mays, Sorghum bicolor, Brachypodium distachyon, Setaria italica, Arabidopsis thaliana, and Oryza sativa) were aligned against the repeat-masked $P$. tenuiflora genome with TBLASTN (Evalue $\leq 10-5$ ) [46], and then Genewise software 2.2.0 was used to predict the gene models [47]. Two strategies were used to assemble the RNA-seq reads to the unique transcripts. First, we mapped the RNA-seq reads to the P. tenuiflora genome with Tophat 2.0.8 [48] and Cufflinks 2.1.1 software [49] (http://cufflinks.cbcb.umd.edu/

Table 4 Overview of the annotation of the $P$. tenuiflora genome

\begin{tabular}{llll}
\hline & & Total Length (bp) & \% of Genome \\
\hline Transposable & DNA & $81,228,002$ & 7.34 \\
Elements & LINE & $33,892,567$ & 3.06 \\
& SINE & 154,638 & 0.01 \\
& LTR & $580,518,664$ & 52.43 \\
& Unknown & $4,544,534$ & 0.41 \\
& Total & $691,362,441$ & 62.44 \\
Types/Copies & Total Length (bp) & \% of Genome $e^{\text {a }}$ \\
RNAs & miRNA (1376) & 171,853 & 0.015522 \\
& tRNA (692) & 52,086 & 0.004704 \\
Protein-coding & rRNA (68) & 14,130 & 0.001276 \\
Genes & SnRNA (702) & 83,103 & 0.007506 \\
& Predicted & Supported by & Supported by \\
& & Transcriptome & Homologs \\
\hline
\end{tabular}


Table 5 General statistics for feature of predicted protein-coding genes of $P$. tenuiflora genome. Protein-coding genes were predicted through the annotation strategy of de novo prediction and evidence based on homology and transcriptome data. The gene model was integrated with EVM and corrected by PASA to obtain the final set of protein-coding genes

\begin{tabular}{|c|c|c|c|c|c|c|c|}
\hline \multicolumn{2}{|l|}{ Gene set } & \multirow{2}{*}{$\begin{array}{l}\text { Number } \\
59,267\end{array}$} & \multirow{2}{*}{$\begin{array}{l}\text { Average gene } \\
\text { length (bp) } \\
1866.04\end{array}$} & \multirow{2}{*}{$\begin{array}{l}\text { Average CDS } \\
\text { length (bp) } \\
873.71\end{array}$} & \multirow{2}{*}{$\begin{array}{l}\text { Average exons per } \\
\text { gene } \\
3.04\end{array}$} & \multirow{2}{*}{$\begin{array}{l}\text { Average exon } \\
\text { length (bp) } \\
287.43\end{array}$} & \multirow{2}{*}{$\begin{array}{l}\text { Average intron } \\
\text { length (bp) } \\
486.52\end{array}$} \\
\hline De novo $^{a}$ & Augustus & & & & & & \\
\hline & GlimmerHMM & 195,821 & 4538.43 & 540.7 & 2.16 & 250.76 & 3457.37 \\
\hline & SNAP & 115,465 & 3464.46 & 615.94 & 2.8 & 220.02 & 1582.94 \\
\hline & Geneid & 122,152 & 2958.40 & 684.27 & 3.08 & 222.01 & 1092.23 \\
\hline & Genscan & 92,436 & 5507.46 & 609.14 & 2.96 & 205.68 & 2497.19 \\
\hline \multirow[t]{6}{*}{ Homolog ${ }^{b}$} & Zea mays & 40,162 & 1988.08 & 978.69 & 3.32 & 294.72 & 434.93 \\
\hline & Sorghum bicolor & 73,561 & 2000.94 & 1121.24 & 2.57 & 436.89 & 561.61 \\
\hline & $\begin{array}{l}\text { Brachypodium } \\
\text { distachyon }\end{array}$ & 67,858 & 2097.32 & 1124.66 & 2.8 & 401.87 & 540.8 \\
\hline & Setaria italica & 62,339 & 1568.92 & 826.04 & 2.68 & 308.16 & 442.05 \\
\hline & $\begin{array}{l}\text { Arabidopsis } \\
\text { thaliana. }\end{array}$ & 43,096 & 1629.35 & 839.3 & 2.77 & 302.45 & 445.1 \\
\hline & Oryza sativa & 76,835 & 1550.38 & 915.3 & 2.35 & 389.23 & 469.88 \\
\hline \multirow[t]{2}{*}{ RNA-seq } & Cufflinks $^{c}$ & 62,560 & 5041.52 & 1845.64 & 5.54 & 333.32 & 704.38 \\
\hline & PASA & 63,952 & 2292.77 & 934.6 & 3.9 & 239.86 & 468.9 \\
\hline \multicolumn{2}{|l|}{ EVM } & 66,649 & 2149.27 & 869.1 & 3.23 & 268.94 & 573.67 \\
\hline \multicolumn{2}{|c|}{ PASA-update } & 66,482 & 2122.71 & 871.22 & 3.22 & 270.77 & 564.36 \\
\hline \multicolumn{2}{|l|}{ Final set ${ }^{c}$} & 39,725 & 2818.49 & 1081.99 & 4.15 & 260.54 & 550.76 \\
\hline
\end{tabular}

${ }^{\text {a }}$ Statistics calculated from the gene set predicted from each method.

${ }^{\text {b }}$ Statistics calculated from the gene set predicted by homolog proteins from each species.

${ }^{C}$ Final results of $P$. tenuiflora genome

). Afterward, we used Trinity [50] to assemble the RNAseq reads, and then used PASA [51] (http://pasapipeline. github.io/) to improve the structure of the assembled genes. We generated non-redundant gene sets using EVidenceModeler (EVM) [52] via integrating gene prediction results of all methods. Finally, the predicted genes were filtered by three criteria: coding region length of $\leq 50$ amino acids; FPKM $<5$; and supported only by de novo strategy. Functions of the proteincoding genes were annotated by BLASTP program (best hit with E-value $\leq 1 \mathrm{E}-05$ ) against three public protein databases: TrEMBL [53], Swiss-Prot, and NR. The protein

Table 6 Functional annotation of protein-coding genes against different databases. Gene functions were obtained from the best BLASTP hit

\begin{tabular}{llll}
\hline Database & & Annotated Number & Annotated Percent (\%) \\
\hline NR & 36,064 & 90.8 \\
Swiss-Prot & 25,684 & 64.7 \\
KEGG & & 24,167 & 60.8 \\
InterPro & aAll & 39,202 & 98.7 \\
& Pfam & 26,709 & 67.2 \\
& GO & 35,648 & 89.7 \\
Total & & 39,470 & 99.4
\end{tabular}

${ }^{\mathrm{a}}$ Combination of Pfam annotation and GO annotation domains were analyzed by InterProScan software (4.8) via searching against InterPro databases 29.0 [54], and the GO term information was collected from the InterPro annotation results [55]. Moreover, we also conducted KEGG annotation for all genes [56].

On the basis of $P$. tenuiflora genomic sequences, we predicted 39,725 protein-coding genes (Tables 5 ). Of the 39,725 predicted protein-coding genes, the protein sequences of 39,470 genes (99.4\%) were similar to sequences of known proteins and could be annotated (Table 6). The average gene length was $2818.5 \mathrm{bp}$, and the average CDS length was $1082.0 \mathrm{bp}$. The average exon number per gene was 4.2, with an average exon length of $260.5 \mathrm{bp}$ and average intron length of $550.8 \mathrm{bp}$ (Table 5).

\section{Annotation of non-coding RNA}

The tRNA genes were discovered with tRNAscan-SE software [57]. The rRNA, miRNA, and snRNA were predicted by INFERNAL software [58] against the Rfam database 9.1 [59]. We annotated non-coding RNA and identified 692 tRNAs, 68 rRNAs, 702 snRNAs, and 1376 microRNAs in the P. tenuiflora genome (Tables 4 and 7). The average lengths of microRNAs, tRNAs, rRNAs, and snRNAs were $124.89 \mathrm{bp}, 75.27 \mathrm{bp}, 207.79 \mathrm{bp}$, and $118.21 \mathrm{bp}$, respectively (Table 7). We deposited the genome sequence in the Genome Warehouse in National Genomics Data Center [60]. 
Table 7 Identification of non-coding RNAs of $P$. tenuiflora genome. The tRNAs were predicted by tRNAscan-SE software. The rRNA, miRNA and snRNA genes were extracted by INFERNAL software against the Rfam database

\begin{tabular}{|c|c|c|c|c|c|}
\hline Type & & Copy & Average length (bp) & Total length (bp) & $\%$ of genome \\
\hline miRNA & & 1376 & 124.89 & 171,853 & 0.015522 \\
\hline tRNA & & 692 & 75.27 & 52,086 & 0.004704 \\
\hline \multirow[t]{5}{*}{ rRNA } & rRNA & 68 & 207.79 & 14,130 & 0.001276 \\
\hline & 185 & 21 & 406.57 & 8538 & 0.000771 \\
\hline & $28 \mathrm{~S}$ & 11 & 129.91 & 1429 & 0.000129 \\
\hline & $5.8 S$ & 4 & 103.5 & 414 & 0.000037 \\
\hline & $5 S$ & 32 & 117.16 & 3749 & 0.000339 \\
\hline \multirow[t]{4}{*}{ snRNA } & snRNA & 702 & 118.21 & 83,103 & 0.007506 \\
\hline & CD-box & 449 & 106.31 & 47,734 & 0.004311 \\
\hline & HACA-box & 65 & 132.71 & 8626 & 0.000779 \\
\hline & splicing & 188 & 141.41 & 26,585 & 0.002401 \\
\hline
\end{tabular}

\section{Assessment of genome quality}

We assessed genome quality using the following methods: Burrow-Wheeler Aligner (BWA), Core Eukaryotic Genes Mapping Approach (CEGMA), and Benchmarking Universal Single-Copy Orthologs (BUSCO). First, in order to assess the quality of genome assembly, we aligned the high-quality Illumina short reads to the assembly using BWA (http://biobwa.sourceforge.net, parameters '-o 1 -i 15') [61]. According to BWA method, $87.41 \%$ of raw reads were mapped to the genome with $93.34 \%$ coverage (Table 8 ). Next, we used CEGMA and BUSCO to estimate completeness of the assembly. CEGMA is a set of conserved protein families for a wide range of eukaryotes, and is used to identify exon-intron structures of these conserved protein families in a new genomic sequence [62]. CEGMA analysis revealed 223 out of 248 ultraconserved eukaryotic genes $(89.9 \%)$ in the $P$. tenuiflora genome indicating integrity for the core genes in the assembly (Table 9). Moreover, completeness of the assembly also was assessed using BUSCO [63] combined with TBLASTN [46], Augustus (version 3.0.2) [40, 41], and HMMER (version 3.1b2) [64]. The BUSCO analysis showed that our assemblies contained $86.8 \%$ complete and $1.7 \%$ fragmented embryophyta orthologs, suggesting that the assembly quality was high (Table 10).

Table 8 Genome coverage rate of raw data based on the BWA method. Mapping rate was generated by mapping raw reads to the $P$. tenuiflora genome to express the reliability of the genome coverage

\begin{tabular}{cll}
\hline & & Percentage \\
\hline Reads & Mapping rate (\%) & 87.41 \\
Genome & Average sequencing depth & 79.35 \\
& Coverage (\%) & 93.34 \\
& Coverage at least 4X (\%) & 90.11 \\
& Coverage at least 10X (\%) & 86.97 \\
& Coverage at least 20X (\%) & 82.46 \\
\hline
\end{tabular}

\section{Utility and discussion}

\section{Description of database}

The genome assembly of $P$. tenuiflora consisted of 14, 036 contigs with a total size of $1.095 \mathrm{~Gb}$. Finally, we assembled 2638 scaffolds with a total size of $1.107 \mathrm{~Gb}$, contig N50 of $117 \mathrm{~kb}$, and scaffold N50 of $950 \mathrm{~kb}$. On the basis of $P$. tenuiflora genomic sequences, we predicted 39,725 protein-coding genes, and identified 692 tRNAs, 68 rRNAs, 702 snRNAs, 1376 microRNAs, and $691 \mathrm{Mb}$ transposable elements. We assessed the quality and completeness of the assembled genome through BWA, CEGMA mapping, and BUSCO mapping (Tables $8,9,10)$. The results showed that our assembly had high quality. All raw data for genome assembly are deposited at NCBI. The genome sequence is deposited in the Genome Warehouse in National Genomics Data Center (https://bigd.big.ac.cn/gwh) (accession number GWHABHL00000000).

\section{Significance of database}

Halophytes belong to several families and are distributed among multiple clades; this broad distribution pattern suggests that the salinity tolerance mechanisms of halophytes have evolved numerous times or have multiple origins [2]. As a result, halophytes not only exhibit a wide range of salinity tolerance but have also evolved diverse molecular and physiological mechanisms for salinity tolerance [2]. This diversity complicates discovery of the salinity tolerance mechanisms of halophytes. To date, almost all known molecular mechanisms of salinity tolerance were characterized in glycophytes such as rice,

Table 9 CEGMA analysis results of $P$. tenuiflora genome

\begin{tabular}{lllllc}
\hline Species & \multicolumn{2}{l}{ Complete } & & \multicolumn{2}{l}{ Complete + partial } \\
\cline { 2 - 3 } \cline { 5 - 6 } & Prots & \% completeness & & Prots & \% completeness \\
\hline P. tenuiflora & 216 & 87.1 & & 223 & 89.92 \\
\hline
\end{tabular}


Table 10 BUSCO results of $P$. tenuiflora genome. C: Complete BUSCOs; S: Complete and single-copy BUSCOs; D: Complete and duplicated BUSCOs; F: Fragmented BUSCOs; M: Missing BUSCOs; n: Total BUSCO groups searched

\begin{tabular}{ll}
\hline Species & BUSCO notation assessment results \\
\hline P. tenuiflora & C:86.8\% [S:75.7\%, D:11.1\%], F:1.7\%, M:11.5\%, n:1440
\end{tabular}

wheat, and Arabidopsis [4-6]. Glycophytes only provide limited insights into mechanisms of salinity tolerance, and extreme halophytes may have enormous values for improving our understanding of salinity tolerance mechanisms. The genome sequence of extreme halophytes will unlock their molecular studies in salinity tolerance.

The Gramineae is an important plant group because it includes many important food crops, such as rice, wheat, maize, and barley. P. tenuiflora, an extreme Gramineae halophyte, is closely related to barley and wheat. Zhang et al. (2013) reported that P. tenuiflora can grow normally for 6 days under $900 \mathrm{mM} \mathrm{NaCl}$ and survive at $\mathrm{pH}$ 11 [23]. Wang et al. (2006) found that P. tenuiflora survived $670 \mathrm{mmol} / \mathrm{L} \mathrm{NaCl}$ [13]. A growing number of molecular biology studies have focused on this species owing to its strong salinity tolerance and high genetic value for cereal improvement [16-28]. In the present study, we sequenced and assembled the $P$. tenuiflora genome $(2 \mathrm{n}=14$, size $1.107 \mathrm{~Gb})$. Our work may improve current understanding of salinity tolerance and provides genetic resources for cereal improvement.

\section{Abbreviations}

BWA: Burrow-Wheeler aligner; CEGMA: Core eukaryotic genes mapping approach; BUSCO: Benchmarking universal single-copy orthologs

\section{Acknowledgements}

Not applicable.

\section{Authors' contributions}

Experiment design: $R G$ and $C Y$; experiment perform: $R G, L Z, K Z$, and $C Y$; data analysis: $R G, C Y, L Z, K Z$, and $D G$; manuscript writing: $R G$, $L Z$, $K Z$, and $C Y$. All authors have read and approved the final manuscript.

\section{Funding}

This work was supported by the National Natural Science Foundation of China (Nos. 31971762,31570328 and 31670218) and Fundamental Research Funds for the Central Universities (No. 2412019FZ026). Genome sequencing was supported by the National Natural Science Foundation of China (nos. 31971762, 31570328 and 31670218) and Fundamental Research Funds for the Central Universities (No. 2412019FZ026). The funding bodies played no role in the design of the study and collection, analysis, and interpretation of data and in writing the manuscript.

\section{Availability of data and materials}

All raw data of genome sequencing are available at NCBI. Accession numbers for raw data of genome assembly are SRR7503009-SRR7503032, and SRP152905 and SRP239345 for transcriptional data. The genome sequence was deposited in the Genome Warehouse in National Genomics Data Center (https://bigd.big.ac.cn/gwh) [60], Beijing Institute of Genomics (BIG), Chinese Academy of Sciences, under accession number GWHABHL00000000 that is publicly accessible at https://bigd.big.ac.cn/ search? $\mathrm{dbld}=\mathrm{g} w h \& \mathrm{q}=\mathrm{GWHABHL} 00000000$ \&page $=1$. Seeds of $P$. tenuiflora is available from the corresponsing author upon request.
Ethics approval and consent to participate

Not applicable.

\section{Consent for publication}

Not applicable.

\section{Competing interests}

The authors declare that they have no competing interests.

\section{Author details}

${ }^{1}$ Key Laboratory of Dryland Agriculture, Institute of Environment and Sustainable Development in Agriculture, Chinese Academy of Agricultural Sciences, Beijing 100081, China. ${ }^{2}$ Key laboratory of Molecular Epigenetics of Ministry of Education (MOE), Northeast Normal University, Changchun 130024, China. ${ }^{3}$ Institute of Genetics and Developmental Biology, Chinese Academy of Sciences, Beijing 100101, China. ${ }^{4}$ Beijing Novogene Bioinformatics Technology Ltd, Beijing 100083, China.

Received: 8 January 2020 Accepted: 13 April 2020

Published online: 19 April 2020

\section{References}

1. Flowers TJ, Yeo AR. Breeding for salinity resistance in crop plants: where next. Aust J Plant Physiol. 1995;22(6):875-84.

2. Flowers TJ, Galal HK, Bromham L. Evolution of halophytes: multiple origins of salt tolerance in land plants. Funct Plant Biol. 2010;37(7):604-12.

3. Yan XF, Sun GR. Physiological Ecology Research of Puccinellia tenuiflora. Beijing: Science Press; 2000 p. 200.

4. Flowers TJ, Colmer TD. Salinity tolerance in halophytes. New Phytol. 2008; 179(4):945-63.

5. Munns R, Tester M. Mechanisms of salinity tolerance. Annu Rev Plant Biol. 2008:59(1):651-81.

6. Flowers TJ. Physiology of halophytes. Plant Soil. 1985;89(1-3):41-56.

7. Wu HJ, Zhang Z, Wang JY, Oh DH, Dassanayake M, Liu B, et al. Insights into salt tolerance from the genome of Thellungiella salsuginea. Proc Natl Acad Sci U S A. 2012;109(30):12219-24.

8. Ma T, Wang J, Zhou G, Yue Z, Hu Q, Chen Y, et al. Genomic insights into salt adaptation in a desert poplar. Nat Commun. 2013;4(1):3797.

9. Guo L, Qiu J, Ye C, Jin G, Mao L, Zhang H, et al. Echinochloa crus-galli genome analysis provides insight into its adaptation and invasiveness as a weed. Nat Commun. 2017;8(1):1031

10. Wang L, Ma G, Wang H, Chen C, Mu S, Wei Q, et al. A draft genome assembly of halophyte Suaeda aralocaspica, a plant that performs C4 photosynthesis within individual cells. GigaSci. 2019;8(9):giz116.

11. Zhao K, Song J, Feng G, Zhao M, Liu J. Species, types, distribution, and economic potential of halophytes in China. Plant Soil. 2011;342(1-2):495509.

12. Meng $X$, Zhao Q, Jin Y, Yu J, Yin Z, Chen S, et al. Chilling-responsive mechanisms in halophyte Puccinellia tenuiflora seedlings revealed from proteomics analysis. J Proteome. 2016;143:365-81.

13. Wang X, Sun G, Wang J, Cao W, Liang J, Yu Z, et al. Relationships among MDA content, plasma membrane permeability and the chlorophyll fluorescence parameters of Puccinellia tenuiflora seedlings under $\mathrm{NaCl}$ stress. Acta Ecol Sin. 2006;26(1):122-9.

14. Xu A. Application of Puccinellia chinampoensis and Puccinellia tenuiflora in Western Jilin Province of China. China Grassl. 1990;2:62-5.

15. Xu H, Bao C, Ge C, Zhang P, Li L. Comparative study for two salt-tolerant herbages Puccinellia tenuiflora and Puccinellia chinampoensis. China Grassl. 1995;14:43-7.

16. Wang YC, Yang CP, Liu GF, Jiang J. Development of a cDNA microarray to identify gene expression of Puccinellia tenuiflora under saline-alkali stress. Plant Physiol Biochem. 2007;45(8):567-76.

17. Wang Y, Chu Y, Liu G, Wang MH, Jiang J, Hou Y, et al. Identification of expressed sequence tags in an alkali grass (Puccinellia tenuiflora) CDNA library. J Plant Physiol. 2007;164(1):78-89.

18. Liu H, Zhang XX, Takano T, Liu SK. Characterization of a PutCAXI gene from Puccinellia tenuiflora that confers $\mathrm{Ca}^{2+}$ and $\mathrm{Ba}^{2+}$ tolerance in yeast. Biochem Biophys Res Commun. 2009;383(4):392-6.

19. Ardie SW, Xie L, Takahashi R, Liu SK, Takano T. Cloning of a high-affinity $\mathrm{K}^{+}$ transporter gene PutHKT2;1 from Puccinellia tenuiflora and its functional 
comparison with OsHKT2; 1 from rice in yeast and Arabidopsis. J Exp Bot. 2009;60(12):3491-502.

20. Ardie SW, Liu SK, Takano T. Expression of the AKT1-type $K^{+}$channel gene from Puccinellia tenuiflora, PutAKT1, enhances salt tolerance in Arabidopsis. Plant Cell Rep. 2010;29(8):865-74.

21. Ardie SW, Nishiuchi S, Liu SK, Takano T. Ectopic expression of the channel $\beta$ subunits from Puccinellia tenuiflora (KPutB1) and rice $(K O B 1)$ alters $\mathrm{K}^{+} / \mathrm{Na}^{+}$ homeostasis of yeast and Arabidopsis. Mol Biotechnol. 2011;48(1):76-86.

22. Yu JJ, Chen SX, Zhao Q, Wang T, Yang CP, Diaz C, et al. Physiological and proteomic analysis of salinity tolerance in Puccinellia tenuiflora. J Proteome Res. 2011;10(9):3852-70.

23. Zhang $X$, Wei L, Wang Z, Wang T. Physiological and molecular features of Puccinellia tenuiflora tolerating salt and alkaline-salt stress. J Integr Plant Biol. 2013;55(3):262-76.

24. Yu JJ, Chen SX, Wang T, Sun GR, Dai SJ. Comparative proteomic analysis of Puccinellia tenuiflora leaves under $\mathrm{Na}_{2} \mathrm{CO}_{3}$ stress. Int J Mol Sci. 2013;14(1): 1740-62.

25. Wang P, Cui YN, Gao L, Wang SM. Construction of RNAi expression vector of CYP86A gene in halophyte Puccinellia tenuiflora. Acta Pratacul Sin. 2017; 26(6):105-10.

26. Zhang WD, Wang P, Bao Z, Ma Q, Duan $L$, Bao AK, et al. SOS1, HKT1:5, and $\mathrm{NHX1}$ synergistically modulate $\mathrm{Na}^{+}$homeostasis in the halophytic grass Puccinellia tenuiflora. Front Plant Sci. 2017:8:576.

27. Ye X, Wang H, Cao X, Jin X, Cui F, Bu Y, et al. Transcriptome profiling of Puccinellia tenuiflora during seed germination under a long-term saline-alkali stress. BMC Genomics. 2019;20(1):589.

28. Yin Z, Zhang H, Zhao Q, Yoo M-J, Zhu N, Yu J, et al. Physiological and comparative proteomic analyses of saline-alkali $\mathrm{NaHCO}_{3}$-responses in leaves of halophyte Puccinellia tenuiflora. Plant Soil. 2019;437(1-2):137-58.

29. Kato A, Lamb JC, Birchler JA, Wessler SR. Chromosome painting using repetitive DNA sequences as probes for somatic chromosome identification in maize. Proc Natl Acad Sci U S A. 2004;101(37):13554-9.

30. Li R, Fan W, Tian G, Zhu H, He L, Cai J, et al. The sequence and de novo assembly of the giant panda genome. Nature. 2010;463(7279):311-7.

31. Kim EB, Fang X, Fushan AA, Huang Z, Lobanov AV, Han L, et al. Genome sequencing reveals insights into physiology and longevity of the naked mole rat. Nature. 2011;479(7372):223-7.

32. Chin C-S, Peluso P, Sedlazeck FJ, Nattestad M, Concepcion GT, Clum A, et al. Phased diploid genome assembly with single molecule real-time sequencing. Nat Methods. 2016;13(12):1050-4.

33. Chin C-S, Alexander DH, Marks P, Klammer AA, Drake J, Heiner C, et al. Nonhybrid, finished microbial genome assemblies from longread SMRT sequencing data. Nat Methods. 2013;10(6):563-9.

34. Walker BJ, Abeel T, Shea T, Priest M, Abouelliel A, Sakthikumar S, et al. Pilon: an integrated tool for comprehensive microbial variant detection and genome assembly improvement. PLoS One. 2014;9(11):e112963.

35. Boetzer M, Henkel CV, Jansen HJ, Butler D, Pirovano W. Scaffolding preassembled contigs using SSPACE. Bioinformatics. 2011;27(4):578-9.

36. Smit AFA, Hubley R. RepeatModeler Open-1.0. 2008-2015. http://www. repeatmasker.org. Accessed 1 Feb 2015.

37. Chen N. Using RepeatMasker to identify repetitive elements in genomic sequences. Curr Protoc Bioinformatics. 2009. https://doi.org/10.1002/ 0471250953.bi0410s25.

38. Price AL, Jones NC, Pevzner PA. De novo identification of repeat families in large genomes. Bioinformatics. 2005;21(1):i351-8.

39. Xu Z, Wang H. LTR-FINDER: An efficient tool for the prediction of full-length LTR retrotransposons. Nucleic Acids Res. 2007:35(2 1):W265-8.

40. Stanke M, Waack S. Gene prediction with a hidden Markov model and a new intron submodel. Bioinformatics. 2003;19(2):ii215-25.

41. Stanke M, Schoffmann O, Morgenstern B, Waack S. Gene prediction in eukaryotes with a generalized hidden Markov model that uses hints from external sources. BMC Bioinform. 2006;7(1):62.

42. Salamov AA, Solovyev W. Ab initio gene finding in Drosophila genomic DNA. Genome Res. 2000;10(4):516-22.

43. Parra G, Blanco E, Guigo R. GenelD in Drosophila. Genome Res. 2000;10(4): $511-5$.

44. Majoros WH, Pertea M, Salzberg SL. TigrScan and GlimmerHMM: two opensource ab initio eukaryotic gene-finders. Bioinformatics. 2004;20(16):2878-9.

45. Korf I. Gene finding in novel genomes. BMC Bioinform. 2004;5(1):59.
46. Altschul SF, Madden TL, Schäffer AA, Zhang J, Zhang Z, Miller W, et al. Gapped BLAST and PSI-BLAST: a new generation of protein database search programs. Nucleic Acids Res. 1997;25(17):3389-402.

47. Birney E, Clamp M, Durbin R. Genewise and genomewise. Genome Res. 2004;14(5):988-95.

48. Trapnell C, Pachter L, Salzberg SL. TopHat: discovering splice junctions with RNA-Seq. Bioinformatics. 2009;25(9):1105-11.

49. Trapnell C, Williams BA, Pertea G, Mortazavi A, Kwan G, van Baren MJ, et al. Transcript assembly and quantification by RNA-Seq reveals unannotated transcripts and isoform switching during cell differentiation. Nat Biotechnol. 2010;28(5):511-5.

50. Grabherr MG, Haas BJ, Yassour M, Levin JZ, Thompson DA, Amit I, et al. Fulllength transcriptome assembly from RNA-Seq data without a reference genome. Nat Biotechnol. 2011;29(7):644-52.

51. Haas BJ, Delcher AL, Mount SM, Wortman JR, Smith RK, Hannick LI, et al. Improving the Arabidopsis genome annotation using maximal transcript alignment assemblies. Nucleic Acids Res. 2003;31(19):5654-66.

52. Haas BJ, Salzberg SL, Zhu W, Pertea M, Allen JE, Orvis J, et al. Automated eukaryotic gene structure annotation using evidence modeler and the program to assemble spliced alignments. Genome Biol. 2008;9(1):R7.

53. Bairoch A, Apweiler R. The SWISS-PROT protein sequence database and its supplement TrEMBL in 2000. Nucleic Acids Res. 2000;28(1):45-8.

54. Mulder N, Apweiler R. InterPro and InterProScan: tools for protein sequence classification and comparison. Methods Mol Biol. 2007;396(2):59-70.

55. Ashburner M, Ball CA, Blake JA, Botstein D, Butler H, Cherry JM, et al. Gene ontology: tool for the unification of biology. Nat Genet. 2000;25(1):25-9.

56. Kanehisa M, Goto S. KEGG: Kyoto encyclopedia of genes and genomes. Nucleic Acids Res. 2000;28(1):27-30.

57. Lowe TM, Eddy SR. tRNAscan-SE: a program for improved detection of transfer RNA genes in genomic sequence. Nucleic Acids Res. 1997;25(5): 955-64.

58. Nawrocki EP, Kolbe DL, Eddy SR. Infernal 1.0: inference of RNA alignments. Bioinformatics. 2009;25(10):1335-7.

59. Griffiths-Jones S, Moxon S, Marshall M, Khanna A, Eddy SR, Bateman A. Rfam: annotating non-coding RNAs in complete genomes. Nucleic Acids Res. 2005;33:D121-4.

60. BIG Data Center Members (BDCM). Database resources of the BIG Data Center in. Nucleic. Acids Res. 2019;47(D1):D8-D14.

61. Li H, Durbin R. Fast and accurate short read alignment with burrowswheeler transform. Bioinformatics. 2009;25(14):1754-60.

62. Parra G, Bradnam K, Korf I. CEGMA: a pipeline to accurately annotate core genes in 2007; 23(9):1061-1067.

63. Simao FA, Waterhouse RM, loannidis P, Kriventseva EV, Zdobnov EM. BUSCO: assessing genome assembly and annotation completeness with single-copy orthologs. Bioinformatics. 2015;31(19):3210-2.

64. Mistry J, Finn RD, Eddy SR, Bateman A, Punta M. Challenges in homology search: HMMER3 and convergent evolution of coiled-coil regions. Nucleic Acids Res. 2013;41(12):e121.

\section{Publisher's Note}

Springer Nature remains neutral with regard to jurisdictional claims in published maps and institutional affiliations.

Ready to submit your research? Choose BMC and benefit from:

- fast, convenient online submission

- thorough peer review by experienced researchers in your field

- rapid publication on acceptance

- support for research data, including large and complex data types

- gold Open Access which fosters wider collaboration and increased citations

- maximum visibility for your research: over $100 \mathrm{M}$ website views per year

At $\mathrm{BMC}$, research is always in progress.

Learn more biomedcentral.com/submissions 